\title{
Melon aroma-producing yeast isolated from coastal marine sediment in Maizuru Bay, Japan
}

\section{AUTHOR(S):}

Sutani, Akitoshi; Ueno, Masahiro; Nakagawa, Satoshi; Sawayama, Shigeki

\section{CITATION:}

Sutani, Akitoshi ...[et al]. Melon aroma-producing yeast isolated from coastal marine sediment in Maizuru Bay, Japan. Fisheries Science 2015, 81(5): 929-936

\section{ISSUE DATE:}

2015-09

URL:

http://hdl.handle.net/2433/202563

\section{RIGHT:}

The final publication is available at Springer via http://dx.doi.org/10.1007/s12562-015-0912-5.; The full-text file will be made open to the public on 28 July 2016 in accordance with publisher's 'Terms and Conditions for Self-Archiving':; This is not the published version. Please cite only the published version.; この論文は出版社版でありません。引用の際には 出版社版をご確認ご利用ください。 
1

2 Topic: Environment

3 Running head: Marine fungus isolation

4

5 Melon aroma-producing yeast isolated from coastal marine sediment in Maizuru Bay,

6 Japan

7

8

9

10

11

12

13

14

15

16

17

182 Maizuru Fisheries Research Station, Field Science Education and Research Center, Kyoto

19 University, Kyoto 625-0086, Japan

\section{FISHERIES SCIENCE ORIGINAL ARTICLE}

Japan

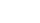

Akitoshi Sutani $^{1} \cdot$ Masahiro Ueno $^{2} \cdot$ Satoshi Nakagawa $^{1} \cdot$ Shigeki Sawayama $^{1}$

.

0 1 12

(Mail) Shigeki Sawayama

sawayama@kais.kyoto-u.ac.jp

15

1 Laboratory of Marine Environmental Microbiology, Division of Applied Biosciences,

7 Graduate School of Agriculture, Kyoto University, Kyoto 606-8502, Japan 
Abstract Researches on marine fungi and fungi isolated from marine environments are not active compared with those on terrestrial fungi. The aim of this study was isolation of novel and industrially applicable fungi derived from marine environments. In this study, 16 fungus-like strains, MS1-MS16, were isolated from coastal marine sediment in Maizuru Bay, Japan, under aerobic culture conditions. Phylogenetic analysis of 18S rRNA gene sequences indicated that 10 isolates belonged to Ascomycota, five isolates belonged to Sordariomycetes, two were Dothideomycetes, and three were Saccharomycetes. Liquid and agar potato dextrose cultures of strains MS1 and MS2 isolated from the coastal sediment released a melon-like aroma. Gas chromatography analysis suggested that strains MS1 and MS2 produce four major chemicals associated with a melon aroma, cis-3-hexen-1-ol, cis-6-nonenal, 3,6-nonadien-1-ol, and trans,cis-2,6-nonadienal. The sequence analyses of the 26S rRNA domains 1/2 (D1/D2) and internal transcribed spacer (ITS) regions indicated that strains MS1 and MS2 were phylogenetically identified as Geotrichum candidum, a well-known yeast used as a cheese starter. These results suggest the future isolations of novel and functional fungi from marine environments.

Key words Marine fungi $\cdot$ Melon-aroma $\cdot$ Yeast $\cdot$ Coastal sediment· Phylogenetic analysis

\section{Introduction}


40 Fungi include a variety of industrially useful species such as Hypocrea jecorina (Trichoderma reesei) and Saccharomyces cerevisiae. H. jecorina produces and secretes a large amount of cellulase, and is a useful industrial enzyme producer. S. cerevisiae has long been used as an ethanol producer $[1,2]$. Terpene glycosides in grapes were reported to be hydrolyzed to free volatile terpene aroma compounds by yeasts during the aging of wines [3]. Ester levels in Bordeaux red wines were strongly influenced by yeast strains [4]. Kluyveromyces lactis and S. cerevisiae were two potent deacidifying and volatile sulphur-aroma producing yeasts of the cheese ecosystem [5]. S. cerevisiae were reported to produce the aroma chemicals of 3-(methylthio)-1-propanol and 3-(methylthio)-propylacetate using L-methionine as sole nitrogen source [6]. Yeasts have a close relationship with flavors and aromas of wines and cheeses.

Marine organisms are thought to be excellent bioresources owing to their production of many useful compounds [7]. Approximately 150-200 new compounds are isolated annually from marine fungi [8]. Marine fungi that produce antimicrobial metabolites have been screened [9]. New prenylxanthones were detected from the deep-sea sediment-derived fungus Emericella sp., which was isolated from the sediment (3,258 m) of the South China Sea [10]. New polyketides were detected from the deep-sea sediment-derived fungus Aspergillus sp., which was isolated from the hydrothermal vent $\left(2,255 \mathrm{~m}\right.$, temperature $\left.114{ }^{\circ} \mathrm{C}\right)$ in the 
southwest Pacific [11]. There may be many uncultured fungal strains that produce useful compounds in marine environments.

Isolated marine fungi have been classified into the phyla Chytridiomycota, Oomycota, Basidiomycota, and Zygomycota. A marine chytridial parasitoid of dinoflagellates has been identified as a new genus and species, Dinomyces arenysensis [12]. A total of 31 fungi isolates were recovered from seawater and sediment samples from the Pearl River Delta (China), and most belonged to the phyla Ascomycota and Basidiomycota [13]. Ninety-eight fungal strains were isolated from two samples of the marine sponge Dragmacidon reticulatum using six different culture media, and 64 distinct fungal ribotypes that belonged to 24 genera of Ascomycota and Zygomycota were obtained [14]. An analysis of internal transcribed spacer (ITS) sequences revealed that 101 phenotypically different fungal isolates obtained from 11 sponge samples collected in King George Island, Antarctica belong to the phylum Ascomycota [15]. There may be many uncultured fungal strains representing a wide range of taxa in marine environments.

The definition of marine fungi is problematic. Marine Ascomycetes have a wide salinity tolerance, including low-salinity conditions, and are less conditioned by the available substrate [16]. The effects of seawater concentration on hyphal growth and antimicrobial metabolite production in marine fungi have been studied using $0 \%, 50 \%$, and $100 \%$ seawater-based culture medium [9]. The aim of this study was isolation of novel and 
industrially applicable fungi derived from marine environments. In this study, fungi were isolated from coastal marine sediment in Maizuru Bay, Japan. Fungi derived from marine sediment habitats were isolated with $100 \%$ seawater-based culture medium. Phylogenetic analyses of the 18S rRNA gene, 26S rRNA domains 1 and 2 (26S rRNA D1/D2), and ITS 1/2 regions were conducted to identify the isolated fungal strains.

\section{Materials and methods}

\section{Sampling and isolation}

A coastal marine surface sediment sample (0-5 cm in depth) was collected using a

Smith-McIntyre sediment sampler from a site in Maizuru Bay (35²9'41.1"N 135²2'05.2"E;

July 19, 2013) in Kyoto prefecture, Japan. The sediment sample was spread on potato dextrose (PD) agar plates based on seawater, and incubated at $25^{\circ} \mathrm{C}$. Colonies that had a fungus-like appearance were selected for further isolation procedures. The isolation procedure was conducted several times to obtain a pure colony appearance using PDA agar plates. Isolated fungus-like strains were designated strains MS1-MS16.

\section{Phylogenetic analyses}


97

Sequence analyses of the 18S rRNA gene, 26S rRNA D1/D2, and ITS regions were conducted.

Isolated fungal strains were incubated in PD liquid medium at $30{ }^{\circ} \mathrm{C}$ and $120 \mathrm{rpm}$ of shaking for $48 \mathrm{~h}$, and cells were collected by centrifugation $(15,000 \times g$ for $10 \mathrm{~min})$. Total DNA was extracted from fungus cells using the FastDNA SPIN Kit for Soil (MP Biomedicals, Solon, OH, USA). DNA fragments of the 18S rRNA gene, 26S rRNA D1/D2, and ITS regions were amplified by polymerase chain reaction with SapphireAmp ${ }^{\circledR}$ Fast PCR Master Mix (Takara Bio, Otsu, Japan).

PCR amplification conditions for the $18 \mathrm{~S}$ rRNA gene were 40 cycles each of $98^{\circ} \mathrm{C}$ for $5 \mathrm{~s}$, $50{ }^{\circ} \mathrm{C}$ for $5 \mathrm{~s}$, and $72{ }^{\circ} \mathrm{C}$ for $15 \mathrm{~s}$ using the specific primer set NS1 and Fungi18S-R (Table 1)

[17]. PCR amplification conditions for the 26S rRNA D1/D2 region were 40 cycles each of $98{ }^{\circ} \mathrm{C}$ for $5 \mathrm{~s}, 56{ }^{\circ} \mathrm{C}$ for $5 \mathrm{~s}$, and $72{ }^{\circ} \mathrm{C}$ for $15 \mathrm{~s}$ using the specific primer set NL1and NL4 (Table 1) [18]. PCR amplification conditions for the ITS regions were 40 cycles each of $98^{\circ} \mathrm{C}$ for $5 \mathrm{~s}, 53{ }^{\circ} \mathrm{C}$ for $5 \mathrm{~s}$, and $72{ }^{\circ} \mathrm{C}$ for $15 \mathrm{~s}$ using the specific primer set ITS1 and ITS4 (Table 1) [19].

PCR products were purified using the High Pure PCR Product Purification Kit (Roche Diagnostics, Mannheim, Germany), and were sequenced using the Applied Biosystems 3730 xl DNA Analyzer (Thermo Fisher Scientific, Waltham, MA, USA). Database searches for similar sequences were conducted using the BLASTN application available at the NCBI website. A multiple sequence alignment was performed using the Clustal Omega program 
116

117

118

119

120

121

122

123

124

125

126

127

128

129

130

131

132

133

134

available at the EMBL-EBI website. A phylogenetic tree was constructed using the

neighbor-joining method implemented in MEGA6.0 [20] with 1,000 bootstrap replicates.

Smittium imitatum or Dipodascus tetrasporeus was used as an outgroup. The sequences of the 18S rRNA gene reported in this study have been deposited in the DDBJ/EMBL/GenBank databases under the accession numbers LC032042 (strain MS1) to LC032051 (strain MS16), 26S rRNA D1/D2 region sequences under LC032052 (strain MS1) to LC032053 (strain MS2), and ITS region sequences under LC032054 (strain MS1) to LC032055 (strain MS2).

\section{Gas chromatography analysis}

Isolated strains MS1 and MS2 were incubated in the PD liquid medium based on seawater at $30{ }^{\circ} \mathrm{C}$ and $120 \mathrm{rpm}$ of shaking for $7 \mathrm{~d}$ in $50-\mathrm{ml}$ vials. Head space gases in the vials were injected into a gas chromatography (GC) apparatus of GC-2010 (Shimadzu, Kyoto, Japan). The column was a ZB-WAX $(0.53 \mathrm{~mm}, 30 \mathrm{~m}$, and $1.0 \mu \mathrm{m})$. The oven temperature was controlled from $60{ }^{\circ} \mathrm{C}$ to $200{ }^{\circ} \mathrm{C}$ at a rate of $1{ }^{\circ} \mathrm{C} \mathrm{min}^{-1}$. Helium was supplied as a mobile phase at $10 \mathrm{ml} \mathrm{min}^{-1}$. GC analyses of standard chemicals associated with a melon aroma were conducted, including cis-3-hexen-1-ol, cis-6-nonenal, 3,6-nonadien-1-ol, and trans,cis-2,6-nonadienal. 


\section{Results}

\section{Biodiversity of fungous strains isolated from the marine sediment collected at Maizuru}

\section{Bay}

Fig. 1

Sixteen fungus-like strains were isolated from the Maizuru Bay marine sediment sample using

PD agar plates under aerobic conditions at $25^{\circ} \mathrm{C}$ (Fig. 1). Phylogenetic analysis using $18 \mathrm{~S}$

rRNA gene sequences indicated that 10 isolates (MS1-MS3, MS6, MS8-MS12, and MS16)

belong to Ascomycota (Fig. 2). Strains MS1-MS3 belong to Saccharomycetes, strains MS10

and MS16 belong to Dothideomycetes, and strains MS6, MS8, MS9, MS11, and MS12

belong to Sordariomycetes. Strains MS1-MS3 were related to species in the genus

Geotrichum, strains MS10 and MS16 were related to species in the genera Fenestella and

Pyrenochaeta, and strains MS6, MS8, MS9, MS11, and 12 were related to species in the

genus Hypocrea. Sequence similarities for the 18S rRNA gene were 95.9\% and 98.5\%

between strain MS1 and G. candidum (X69842) and between strain MS2 and G. candidum

(X69842), respectively.

\section{Identifications of the volatile substances corresponding to culture aroma}

Fig. 3

Strains MS1 and MS2 produced a melon-like aroma on agar PD plates and in liquid PD 
155

156

157

158

159

160

161

162

163

164

165

culture medium. The cells of strains MS1 and MS2, related to the genus Geotrichum, had a yeast-like form (Fig. 3). The cell length of strain MS1 was 7-9 $\mu \mathrm{m}$, and that of strain MS2 was 7-13 $\mu \mathrm{m}$. Gas chromatograms of strains MS1 and MS2 are shown in Fig. 4. GC analysis indicated that strains MS1 and MS2 produce cis-3-hexen-1-ol, cis-6-nonenal, 3,6-nonadien-1-ol, and trans,cis-2,6-nonadienal in the liquid PD culture. GC chromatograms show that there are additional volatile compounds in the head space gases of strains MS1 and MS2. The chromatograms of strains MS1 and MS2 indicate a similar pattern.

\section{Fingerprinting of the yeast strains producing the melon aroma}

Phylogenetic analysis of strains MS1 and MS2 based on the 26S rRNA D1/D2 region sequence indicated that these two strains form an monophyletic clade with G. candidum

CBS178.71, G. candidum CBS607.85, G. candidum CBS11628, and G. candidum CBS11616

(Fig. 5). Sequence similarities for the $26 \mathrm{~S}$ rRNA D1/D2 region were $99.3 \%$ and $99.6 \%$

between MS1 and Galactomyces candidum CBS11616 (JN974264) and between MS2 and G. candidum CBS11616 (JN974264), respectively. Geotrichum phurueaensis, Galactomyces pseudocandidum, Geotrichum europaeum, and Galactomyces geotrichum form an monophyletic clade. Galactomyces reessii and Galactomyces citri-aurantii form an monophyletic clade. The sequence analyses of strains MS1 and MS2 based on the 26S rRNA 
174

175

176

177

178

179

180

181

182

183

184

D1/D2 region showed that these two strains were phylogenetically identified as G. candidum

(Fig. 5).

Fig. 5

Sequence analysis of the ITS region showed that strain MS1 forms a clade with $G$.

candidum Tom1 and G. candidum 282A (Fig. 6). Sequence similarities for the ITS region

were 99.6\% and 99.6\% between strain MS1 and G. candidum Tom1 (KF298071) and between

strain MS1 and G. candidum 282A (KF669518), respectively. The sequence of strain MS1

was relatively similar to those of G. candidum L19PB, G. candidum L13PC, and G. candidum

L20B. Strain MS2 formed a clade with G. candidum Thu1. The sequence similarity for the

ITS region was 98.6\% between strain MS2 and G. candidum Thu1 (KF298070). The

sequence of strain MS2 was relatively similar to those of G. candidum Gou1, G. candidum

Que1, G. candidum Mah2, G. candidum CBS178.71, and G. candidum CBS11176. Strains

MS1 and MS2 were not closely related to G. reessii, G. citri-aurantii, or G. pseudocandidum.

The sequence analyses of strains MS1 and MS2 based on the ITS region indicated that these

two strains were phylogenetically identified as G. candidum (Fig. 6).

\section{Discussion}

Sixteen fungus-like colonies were isolated from Maizuru Bay surface sediment. Ten isolates

belong to Ascomycota based on a phylogenetic analysis. Representatives of the genera 
193

194

195

196

197

198

199

200

201

202

203

204

205

Penicillium and Hypocrea were the most diverse and abundant fungi isolated from marine

sponges [14]. In the present study, 5 strains in the genus Hypocrea were isolated from coastal sediment. Hypocrea may be one of the most frequent genus isolated from marine

environments. Isolated marine fungi have previously been classified as belonging to the phyla Chytridiomycota, Oomycota, Ascomycota, Basidomycota, and Zygomycota [13,14]. The presently isolated fungi from the coastal marine sediment do not show substantial phylogenetic divergence.

Phylogenetic 18S rRNA gene sequence analysis showed that strains MS1 and MS2 were related with the genus Geotrichum, phylum Ascomycota, class Saccharomycetes, order

Saccharomycetales, family Endomycetaceae. The 26S rRNA D1/D2 and ITS sequence analyses indicated that strains MS1 and MS2 were phylogenetically identified as G. candidum.

G. candidum is known as a plant pathogenic fungus and is used for rind formation during Camembert cheese production [21, 22]. Geotrichum candidum refers to an anamorph and Galactomyces candidus refers to a teleomorph [19, 23]. In the present study, strain MS1 is designated Geotrichum candidum MS1, and strain MS2 is designated Geotrichum candidum MS2. There could be confusion regarding whether Galactomyces candidus and Galactomyces candidum is the appropriate species name. The original species names used in the associated references or gene databases are used in this paper. 
212 melon-like aroma. Volatile analysis indicated that the melon aroma resulted from acetones,

213 non-acetone esters, sulfur-containing compounds, alcohols, and aldehydes [24]. Important

214 chemicals known to cause a melon aroma are cis-3-hexen-1-ol, cis-6-nonenal,

215 3,6-nonadien-1-ol, and trans,cis-2,6-nonadienal [24, 25]. GC analysis suggested that strains

216 MS1 and MS2 produce these four major melon-aroma chemicals. G. candidum isolated from

217 sludge of an aerated pilot-scale bubble column was reported to produce a pineapple-like

218 aroma [26]. It produces ethyl esters of acetic acid and butyric acid, methyl-3-butan-1-ol, and

219 methyl-2-propan-1-ol with glucose [26]. Strains MS1 and MS2 produce cis-3-hexen-1-ol,

220 cis-6-nonenal, 3,6-nonadien-1-ol, and trans,cis-2,6-nonadienal; therefore, different strains of

G. candidum could produce different kinds of compounds associated with fruity aromas.

Production of volatile compounds by Geotrichum fragrans using cassava wastewater as

substrate has also been reported [27]. The newly isolated fungal strains of MS1 and MS2

might be applicable for melon-aromatic food.

G. candidum directly and positively contributes to cheese ripening and flavor development

of many soft and semi-hard cheeses [28, 29]. In Camembert cheese production, G. candidum

grows on the outside of the cheese and contributes to the formation of a rind [22, 30]. ITS

region sequence analysis suggested that strain MS1 is similar to G. candidum Tom1. Strain 
231 from soft cheese, Thurgauer weinkäse, in Switzerland [31]. ITS sequences of G. candidum

232 strains L13PC, L19PB, L20BK, and 282A were reported from cheese-related studies

233 (unpublished data recorded in DDBJ/EMBL/GenBank). Strains MS1 and MS2 are closely

234 related to G. candidum strains isolated from cheese; therefore, there is a possibility of using

235 the presently isolated two yeast strains for cheese ripening. Galactomyces Ferment Filtrate is

236 used to produce cosmetics such as facial treatment essence, clear lotion, and masks. It is

237 reported to have markedly increased caspase-14 expression [32]. Capase-14 expression

238 prevents epidermal UVB damage and water loss [33]. Phylogenetic information regarding this

239 Galactomyces sp. is not available; therefore, further research is necessary to determine

240 whether the ferment filtrates of strains MS1 and MS2 have similar activity.

241 The present study confirmed that marine environments harbor a diversity of unknown fungi

242 with unique features, and further physiological researches on marine fungi are very important

243 for applied and environmental microbiology. Considering industrial application in Japan, it is

244 advantageous that the fungal strains of MS1 and MS2 with melon-aroma were newly isolated

245 from Japanese territorial sea.

Acknowledgements We are grateful to Dr. K. W. Suzuki, Mr. S. Akiyama, and Mr. K.

Watanabe (Kyoto University) for technical assistance in sediment sampling, and Dr. M. 
249

250

251

252

253

254

255

256

257

258

259

260

261

262

263

264

265

266

267

Morikawa (S \& A Lab) for technical assistance in GC analysis. This work was financially

supported by Institute for Fermentation, Osaka.

\section{References}

1. Kubicek CP (2013) Systems biological approaches towards understanding cellulase production by Trichoderma reesei. J Biotechnol 163:133-142

2. Dombek KM, Ingram LO (1987) Ethanol production during batch fermentation with Saccharomyces cerevisiae: changes in glycolytic enzymes and internal pH. Appl Environ Microbiol 53:1286-1291

3. Ebler SE, Thoengate JH (2009) Wine chemistry and flavor: looking into the crystal glass.

$$
\text { J Agric Food Chem 57:8098-8108 }
$$

4. Gammacurta M, Marchand S, Albertin W, Moine V, de Revel G (2014) Impact of yeast strain on ester levels and fruity aroma persistence during aging of Bordeaux red wines. J Agric Food Chem 62:5378-5389

5. Kagkli DM, Tâche R, Cogan TM, Hill C, Casaregola S, Bonnarme P (2006) Kluyveromyces lactis and Saccharomyces cerevisiae, two potent deacidifying and volatile-sulphur-aroma-producing microorganisms of the cheese ecosystem. Appl Microbiol Biotechnol 73:434-442

6. Etschmann MMW, Kötter P, Hauf J, Bluemke W, Entian KD, Schrader J (2008) 
Production of the aroma chemicals 3-(methylthio)-1-propanol and

3-(methylthio)-propylacetate with yeasts. Appl Microbiol Biotechnol 80:579-587

7. Kiuru P, D’Auria MV, Muller CD, Tammela P, Vuorela H, Yli-Kauhaluoma J (2014)

Exploring marine resources for bioactive compounds. Planta Med 80:1234-1246

272

8. Blunt JW, Copp BR, Keyzers RA, Munro MHG, Prinsep MR (2014) Marine natural products. Nat Prod Rep 31:160-258

9. Masuma R, Yamanaguchi Y, Noumi M, Omura S, Michio N (2001) Effect of sea water concentration on hyphal growth and antimicrobial metabolite production in marine fungi. Mycosci 42:455-459

10. Fredimoses M, Zhou X, Lin X, Tian X, Ai W, Wang J, Liao S, Liu J, Yang B, Yang X, Liu Y (2014) New prenylxanthones from the deep-sea derived fungus Emericella sp. SCSIO 05240. Mar Drugs 12:3190-3202

11. Chen XW, Li CW, Cui CB, Hua W, Zhu TJ, Gu QQ (2014) Nine new and five known $12: 3116-3137$

12. Lepelletier F, Karpov SA, Alacid E, Le Panse S, Bigeard E, Garcés E, Jeanthon C, Guillou L (2014) Dinomyces arenysensis gen. et sp. nov. (Rhizophydiales, 
287

288

289

290

291

292

293

294

295

296

297

298

299

300

301

302

303

304

305

306

13. Li L, Singh P, Liu Y, Pan S, Wang G (2014) Diversity and biochemical features of culturable fungi from the coastal waters of Southern China. AMB Express. 30:4, 60

14. Passarini MR, Santos C, Lima N, Berlinck RG, Sette LD (2013) Filamentous fungi from the Atlantic marine sponge Dragmacidon reticulatum. Arch Microbiol 195:99-111

15. Henriquez M, Vergara K, Norambuena J, Beiza A, Maza Fe, Ubilla P, Araya I, Chavez R, San-Martin A, Darias J, Darias MJ, Vaca I (2013) Diversity of cultivable fungi associated with Antarctic marine sponges and screening for their antimicrobial, antitumoral and antioxidant potential. World J Microbiol Biotechnol 30:65-76

16. Byrne PJ, Jones EBG (1975) Effect of salinity on the reproduction of terrestrial and marine fungi. Trans Br Mycol Soc 65:185-200

17. Chen Y, Chen Z, Guo R, Chen N, Lu H (2011) Correlation between gastrointestinal fungi and varying degrees of chronic hepatitis B virus infection. Diagn Microbiol Infect Dis $70: 492-498$

18. Yalçın HT, Çorbacı CF, Uçar B (2014) Molecular characterization and lipase profiling of the yeasts isolated from environments contaminated with petroleum. J Basic Microbiol 54:S85-S92

19. Hong GS, Smith MT (2004) Ribosomal gene phylogeny and species delimitation in Geotrichum and its teleomorphs. Studies Mycol 50:489-515

20. Tamura K, Stecher G, Peterson D, Filipski A, Kumar S (2013) MEGA6: molecular evolutionary genetics analysis version 6.0. Mol Biol Evol 30:2725-2729 
307

308

309

310

311

312

313

314

315

316

21. Thornton CR, Slaughter CD, Davis RM (2010) Detection of the sour-rot pathogen

Geotrichum candidum in tomatoes fruit and juice by using a highly specific monoclonal antibody-based ELISA. Int J Food Microbiol 143:166-172

22. Lessard MH, Bélanger G, St-Gelais D, Labrie S (2012) The composition of Camembert cheese-ripening cultures modulates both mycelial growth and appearance. Appl Environ Microbiol 78:1813-1819

23. Alper I, Frenette M, Labrie S (2011) Ribosomal DNA polymorphisms in the yeast Geotrichum candidum. Fungal Biol 115:1259-1269

24. Lignou S, Parker JK, Baxter C, Mottram DS (2014) Sensory and instrumental analysis of medium and long shelf-life Charentais cantaloupe melons (Cucumis melo L.) harvested at different maturities. Food Chem 148:218-229

25. Allwood JE, Cheung W, Xu Y, Mumm R, De Vos RCH, Deborde C, Biais B, Maucourt M, Berger Y, Schaffer AA, Rolin D, Moing A, Hall RD, Goodacre R (2014) Metabolomics in melon: A new opportunity for aroma analysis. Phytochemistry 99:61-72

26. Mdaini N, Gargo M, Hammami M, Monser L, Hamdi M (2006) Production of natural fruity aroma by Geotrichum candidum. Appl Biochem Biotechnol 128:127-136

27. Damasceno SM, Cereda P, Pastore GM, Oliveira JG (2008) Production of volatile compounds by Geotrichum fragrans using cassava wastewater as substrate. Process Biochem 39:411-414 
326

327

328

329

330

331

332

333

334

28. Boutrou R, Gueguen M (2005) Interests in Geotrichum candidum for cheese technology. Int J Food Microbiol 102:1-20

29. Missous G, Thammavongs B, Dieuleveux V, Houssin M, Henry J, Panoff J (2012) Proteomic expression of microfungal ripening starter Geotrichum candidum submitted to cold stress is strain-dependent: study using 2D-dige technology and samespots software analysis. CryoLetters 33:289-298

30. Leclercq-Perlat MN, Sicard M, Trelea IC, Picque D, Corrieu G (2012) Temperature and relative humidity influence the microbial and physicochemical characteristics of Camembert-type cheese ripening. J Dairy Sci 95:4666-4682

31. Marin P, Palmero D, Jurado M (2014) Effect of solute and matric potential on growth rate of fungal species isolated from cheese. Int Dairy J 36:89-94

32. Kataoka S, Hattori K, Date A, Tamura H (2013) Human keratinocyte caspase-14 expression is altered in human epidermal 3D models by dexamethasone and by natural products used in cosmetics. Arch Dermatol Res 305:683-689

33. Denecker G, Hoste E, Gilbert B, Hochepied T, Ovaere P, Lippens S, Van den Broecke C, Van Damme P, D’Herde K, Hachem JP, Borgonie G, Presland RB, Schoonjans L, Libert C, Vandekerckhove J, Gevaert K, Vandenabeele P, Declercq W (2007) Caspase-14 protects against epidermal UVB photodamage and water loss. Nat Cell Biol 9:666-674 
Table 1 List of primers used in this study

\begin{tabular}{|c|c|c|c|}
\hline Primer name & Sequence (5’-3’) & Amplification & Reference \\
\hline & & target & \\
\hline \multirow[t]{2}{*}{ NS1 } & GTAGTCATATGCTTGTCTC & 18S rRNA & 17. Chen et \\
\hline & & gene & al. 2011 \\
\hline \multirow[t]{2}{*}{ Fungi18S-R } & GATCCCTAGTCGGCATAGTT & 18S rRNA & 17. Chen et \\
\hline & & gene & al. 2011 \\
\hline \multirow[t]{3}{*}{ NL1 } & GCATATCAATAAGCGGAGGAAAAG & 26S rRNA & 18. Yalçın \\
\hline & & gene $\mathrm{D} 1 / \mathrm{D} 2$ & et al. 2014 \\
\hline & & region & \\
\hline \multirow[t]{3}{*}{ NL4 } & GGTCCGTGTTTCAAGACGG & 26S rRNA & 18. Yalçın \\
\hline & & gene D1/D2 & et al. 2014 \\
\hline & & region & \\
\hline \multirow[t]{2}{*}{ ITS1 } & TCCGTAGGTGAACCTGCGG & IST region & 19. Hong et \\
\hline & & & al. 2004 \\
\hline \multirow[t]{2}{*}{ ITS4 } & TCCTCCGCTTATTGATATGC & IST region & 19. Hong et \\
\hline & & & al. 2004 \\
\hline
\end{tabular}




\section{Figure legends}

Fig. 1 Photographs of fungus-like colonies of strains MS1-MS16 isolated from the Maizuru Bay marine sediment.

Fig. 2 Phylogenetic tree including 10 isolated fungal strains from the Maizuru Bay marine sediment and authentic fungal strains based on the 18S rRNA gene sequences. The tree was constructed using the neighbor-joining algorithm with bootstrap analyses (1,000 replicates) using MEGA6. Accession numbers were shown in parentheses. The scale bar represents 0.05 of estimated sequence divergence. S. imitatum was used as an outgroup.

Fig. 3 Photographs of the cells of strain MS1 (a) and strain MS2 (b). These were photographed at magnification of 1,000 times by an optical microscope.

Fig. 4 Gas chromatograms of culture head gases for strains MS1 (a) and MS2 (b). Four chemicals, cis-3-hexen-1-ol, cis-6-nonenal, 3,6-nonadien-1-ol, and trans,cis-2,6-nonadienal, known as the main components of melon aroma were used for external standards.

Fig. 5 Phylogenetic tree for isolated strains MS1 and MS2 generated from 26S rRNA gene D1/D2 region sequences. The tree was constructed using the neighbor-joining algorithm with bootstrap analyses (1,000 replicates) using MEGA6. Gal. means genus Galactomyces, and Geo. means genus Geotrichum. Accession numbers were shown in parentheses. The scale bar represents 0.01 of estimated sequence divergence. D. tetrasporeus was used as an outgroup.

Fig. 6 Phylogenetic tree for isolated strains MS1 and MS2 generated from ITS region 
373 sequences. The tree was constructed using the neighbor-joining algorithm with bootstrap 374 analyses (1,000 replicates) using MEGA6. Gal. means genus Galactomyces, and Geo. means 375 genus Geotrichum. Accession numbers were shown in parentheses. The scale bar represents 3760.02 of estimated sequence divergence. D. tetrasporeus was used as an outgroup. 


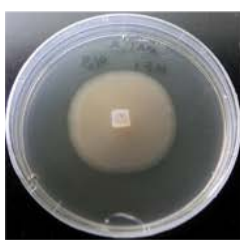

MS1

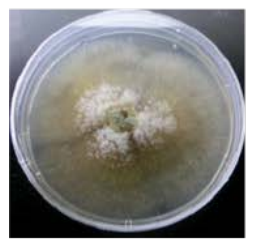

MS7

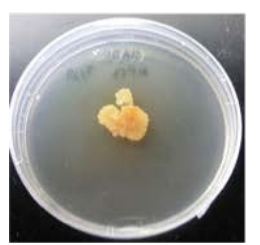

MS13

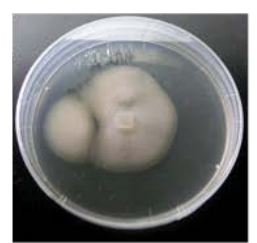

MS2

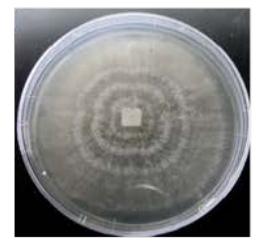

MS8

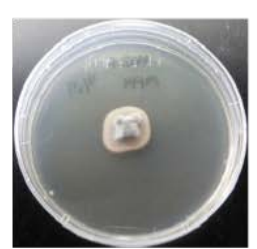

MS14

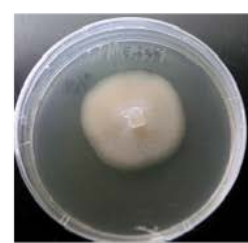

MS3

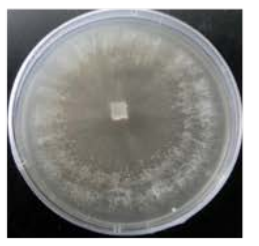

MS9

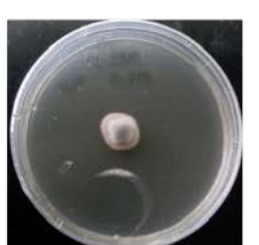

MS15

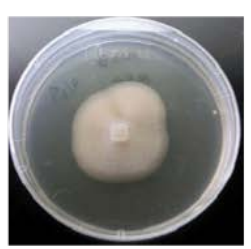

MS4

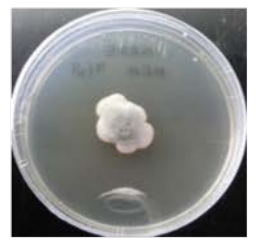

MS10

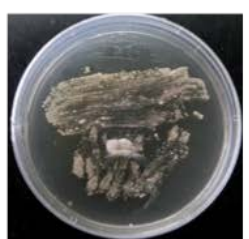

MS16

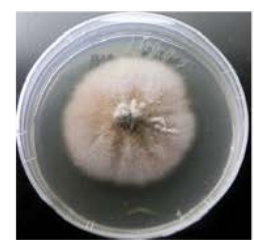

MS5

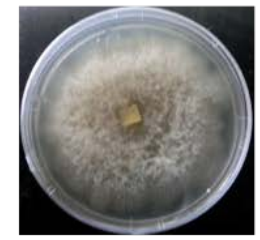

MS11

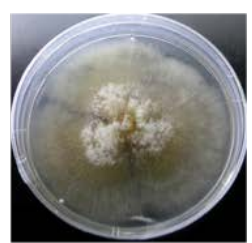

MS6

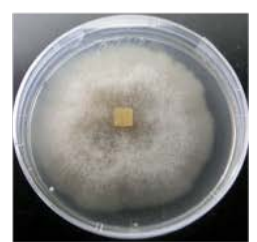

MS12

397

398

399

400

401

402

403

404

405 


\section{MS8}

${ }_{85}$ Hypocrea jecorina (JN831373)

MS6

69

MS11

MS12

- Fusarium oxysporum (AB110910)

100

Colletotrichum Iupini (JN939848)

- Cladosporium cladosporioides (AF548070)

Phoma glomerata (AY293783)

$59{ }_{78}$ Pyrenochaeta nobilis (DQ898287)

$86{ }^{78}$ Fenestella fenestrata (GU205238)

91 MS16

MS10

Scheffersomyces stipitis (AB054280)

97 Candida albicans (AB013586)

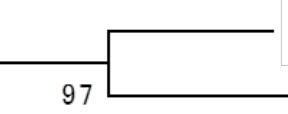

Dipodascus albidus (X69840)

Galactomyces citri-aurantii (AB000664)

$81 \quad$ Galactomyces reessii (AB000646)

96 [ Geotrichum candidum (X69842)

\section{MS1}

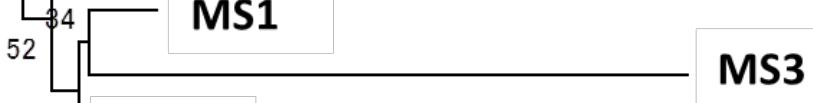


436

437

438

439

440

441

442

443

444

445

446

447

448

449

450

451

b

452

453

454

455

456

457

458

$10 \mu \mathrm{m}$

$10 \mu \mathrm{m}$

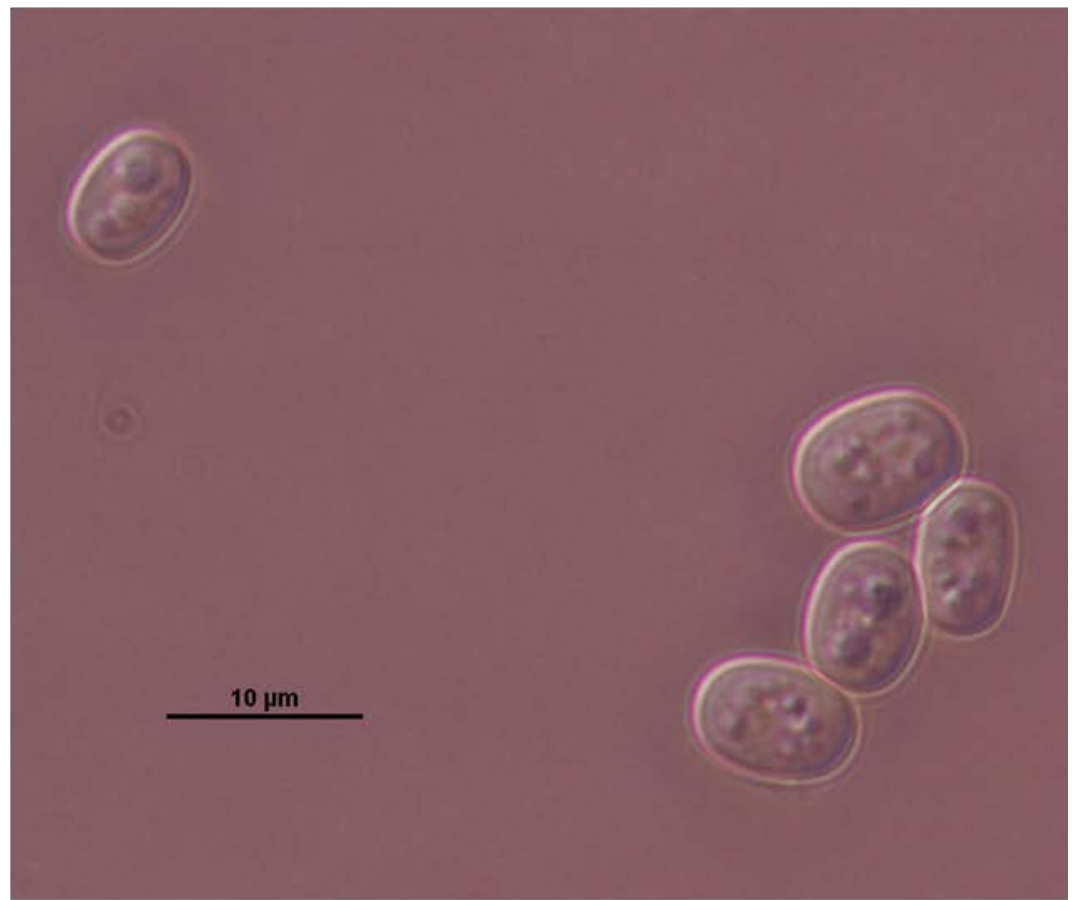

a

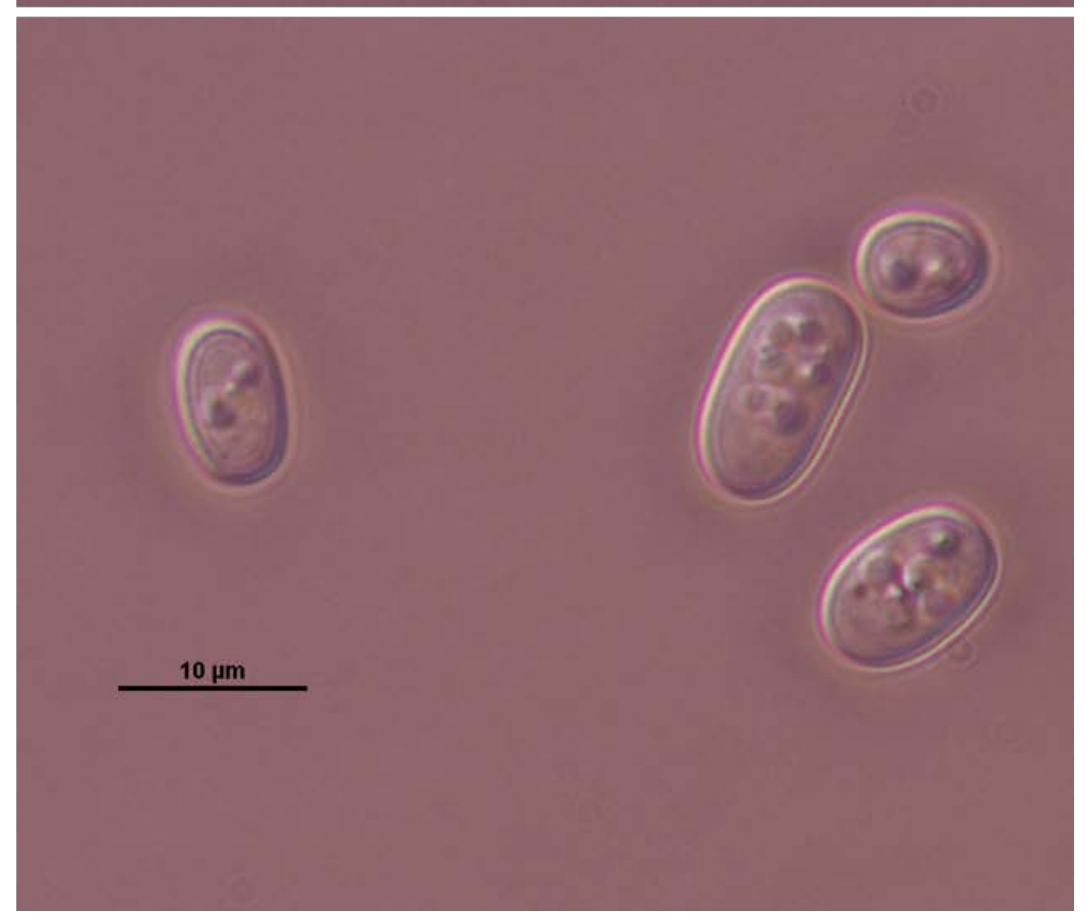

461

462

463

Fig. 3 Sutani et al.

464 
465

466

467

468

469

a

470

471

472

473

474

475
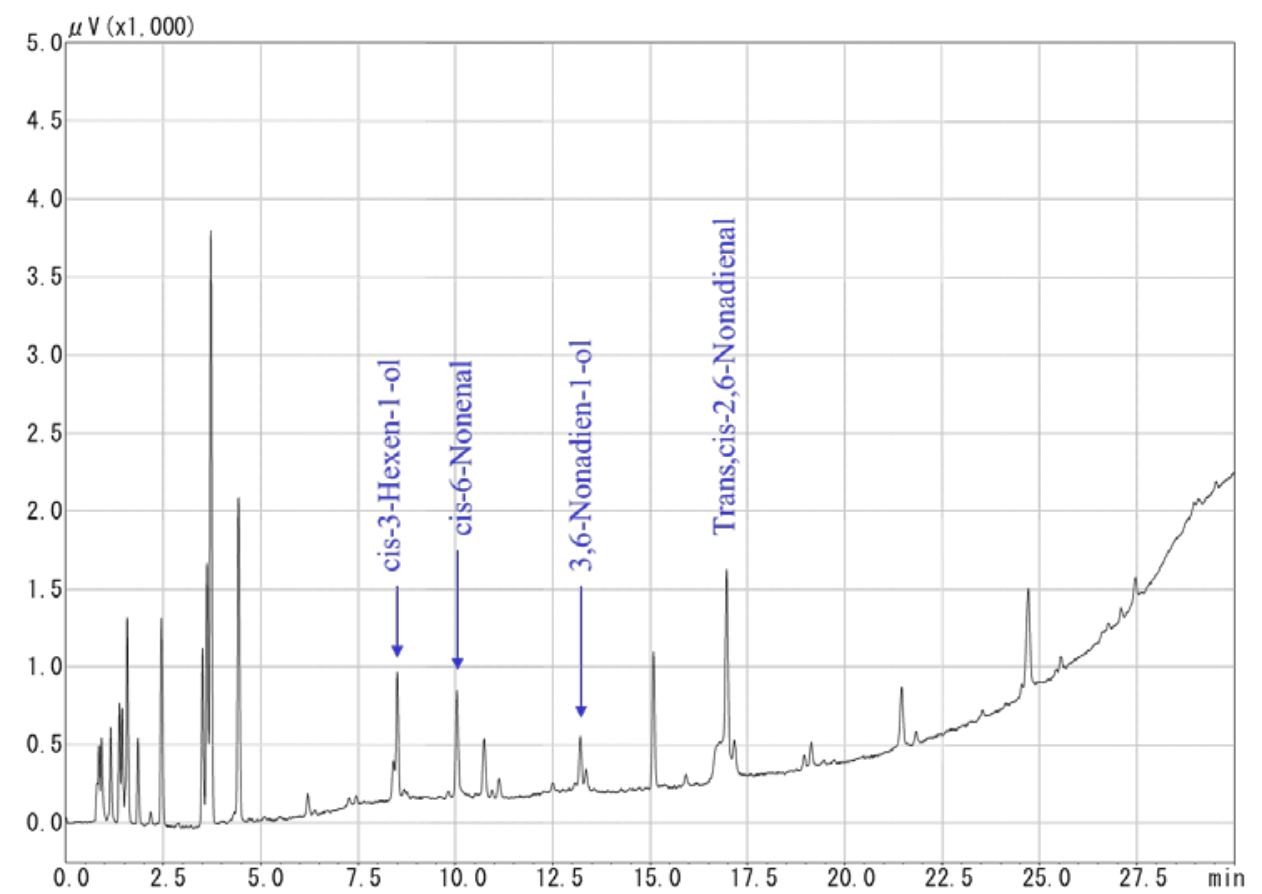

476

477

478

479

480

481

482

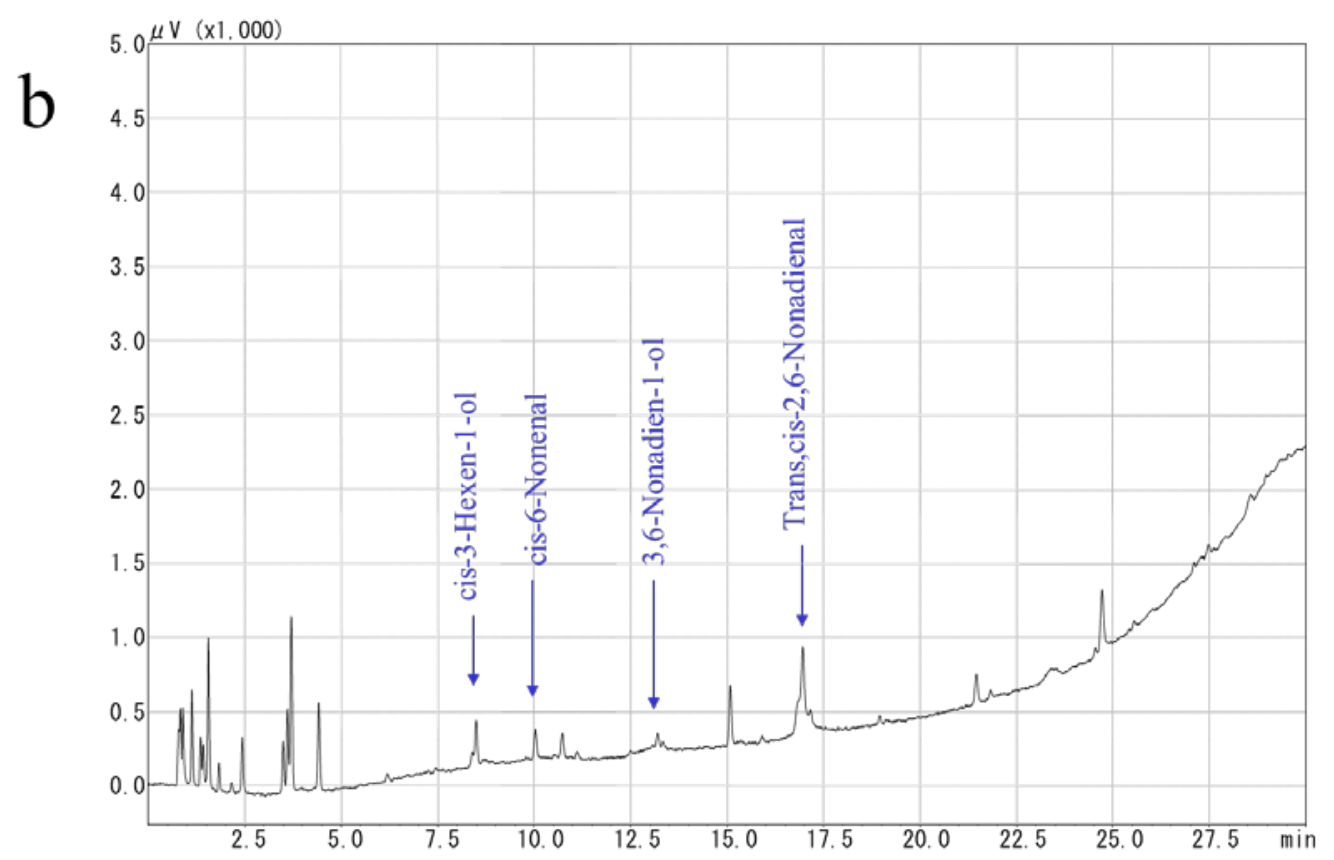

483

Fig. 4 Sutani et al. 
485

486

487

488

489

490

491

492

493

494

495

496

497

498

499

500

501

502

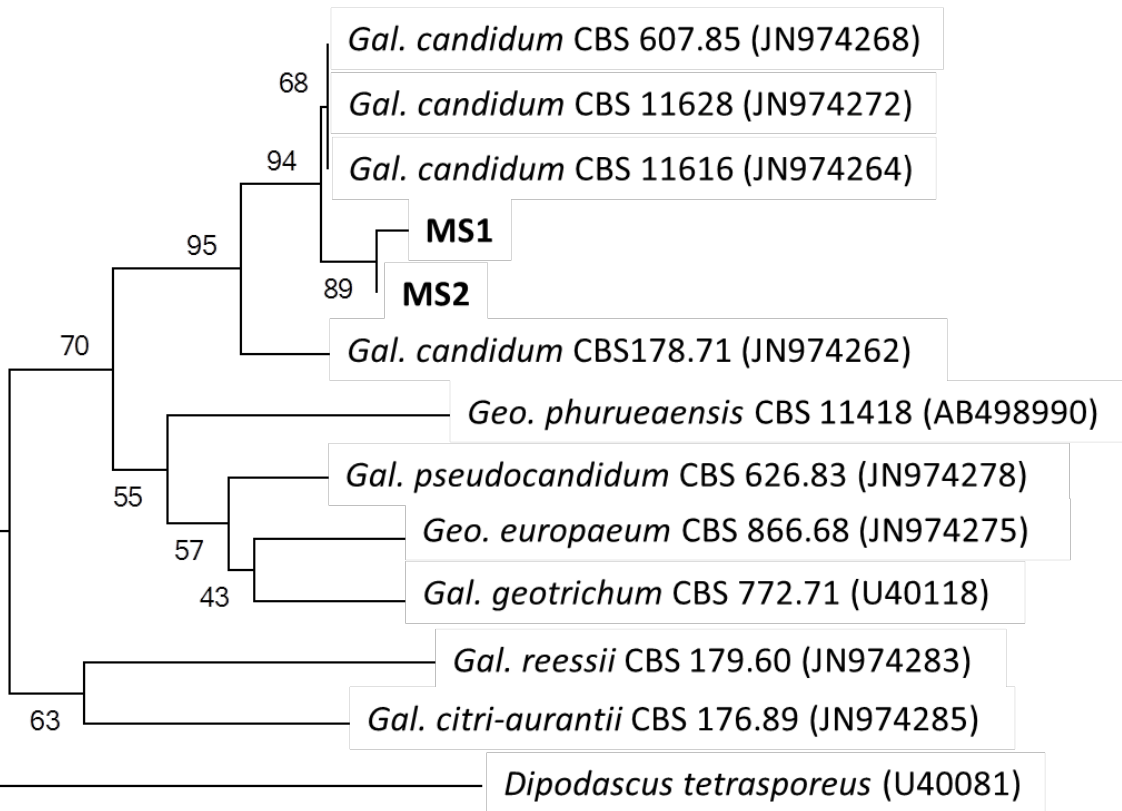

503

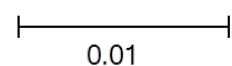

504

505

506

507

508

509

510

511

512

Fig. 5 Sutani et al.

513 
526

527

528

529

530

531

532

533

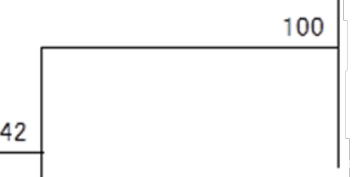

Gal. candidum CBS11176 (JN974290) Gal. candidum CBS178.71 (KF984491) Geo. candidum Mah2 (KF298068) Geo. candidum Que1 (KF298069) Geo. candidum Gou1 (KF298067)

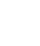

